\title{
Rural Secondary School Teachers' Capacity to Respond to Hiv and Aids: The Case of Shurugwi District in Zimbabwe
}

\author{
Ezron Mangwaya $^{1} \&$ Emily $\mathrm{Ndlovu}^{2}$ \\ ${ }^{1}$ Department of Educational Foundations, Midlands State University, Gweru, Zimbabwe \\ ${ }^{2}$ Department of Educational Foundations, Lupane State University, Bulawayo, Zimbabwe \\ Correspondence: Ezron Mangwaya, Department of Educational Foundations, Midlands State University, P. B. \\ 9055 Gweru, Zimbabwe. E-mail: mangwayaezron@yahoo.co.uk
}

Received: October 20, 2012 Accepted: December 5, 2012 Online Published: January 28, 2012

doi:10.5539/ass.v9n2p129

URL: http://dx.doi.org/10.5539/ass.v9n2p129

\begin{abstract}
Young people often turn to their teachers for information on sexuality and HIV and Aids. Consequently teachers need to be not only knowledgeable about these issues but also able to integrate them into their teaching. As part of an umbrella study to investigate and promote HIV and Aids education and support in schools, this article reports on a qualitative study conducted among a purposively selected sample of teachers in Shurugwi schools to ascertain their response to the challenges resulting from the pandemic. The findings suggest that the participating teachers held complex and contradictory views about HIV and Aids education; that they were constrained by the prevailing social and cultural background; and that their responses were inhibited by the lack of adequate social welfare support systems. These factors combined to make it difficult for them to interpret and implement policy that calls for a coherent and collaborative response. This study will hopefully inform professional development interventions to ensure that future HIV and AIDS teaching and learning is relevant and effective, given the social and educational context.
\end{abstract}

Keywords: teaching, HIV and AIDS, secondary schools

\section{Introduction}

The HIV/AIDS pandemic is not only eroding the capacity of the education sector to meet its core objectives of providing quality education for all, but is placing demands on schools, and ultimately on teachers, which they are not equipped to deal with (Cohen,2002). In this era of multi-literacies, HIV and AIDS 'literacy' is becoming an increasingly important determining factor for teachers in their ability to deal with the challenges and stresses facing them, as a direct or indirect consequence of the pandemic. Teachers not only need to be able to understand the bio-medical facts of the virus, but also have to come to a deep understanding of the complex web of related cultural, economic and social causes and consequences of the pandemic (Chege,2006). Such an understanding is a necessary foundation to enable them to integrate effective HIV and AIDS education into their teaching, and to intervene to ensure that the basic physiological and psychosocial needs of their learners are met. Teachers operating in such difficult social and educational circumstances also have to develop resilience to ensure that their own mental health is not jeopardized (Theron, 2007).

It is questionable whether the majority of teachers have the capacity to respond as described above. Note however that since, of all adults, teachers are the group which the youth turn to for information and advice on sexuality-related matters it is imperative that they are assisted to develop a high level of competence and confidence regarding HIV and AIDS education. The knowledge, attitude and capacity of teachers to respond should therefore be explored, as a point of departure for future developmental interventions. Although there is evidence that education is not an adequate buffer against HIV infection (Berger, 2004), particularly among women, the reality is that formal education remains a bastion of hope in the fight against HIV and AIDS. Schools and teachers are in an ideal position to positively influence learners to make choices that will lessen their vulnerability to HIV infection and to help them deal with the socio- economic and psychological consequences of being infected or affected. However the counter-argument exists that the school environment may well become an incubator for attitudes and behaviours that contribute to the spread of HIV (Clarke,2005).Negative peer pressure and the 'wrong things' being taught could be contributory factors.

In order to lessen the possibility of such a scenario, we propose that teachers would benefit from training that 
would help them approach HIV and AIDS education in a comprehensive and critical manner. To do this they would need to be able to obtain and accurately interpret information about HIV and AIDS prevention and care from a global and holistic perspective; to use this knowledge to design and implement educational programmes as a preventative measure against HIV infection (Coombe,2002); to minimize related stigma, providing care and emotional and practical support to those in need; to create emotional environments that encourage trust and openness; and to be able to protect their own professional and personal well-being to prevent overload and burn-out. Being HIV and AIDS literate also entails the adoption of a critical stance, interrogating whether specific knowledge and practices are suitable for specific contexts, rather than just blindly implementing curricula/programs provided by external experts. It involves a critique of prevalent discourses that permeate the view of HIV as an irreversible disaster, a view that writes off the future of learners infected / affected by HIV and AIDS. Although not everyone agrees that teachers should be expected to take on such responsibilities (De Lannoy,2005) the Zimbabwe National Policy on HIV and AIDS as well as the associated ministerial policies stipulate that teachers should be able to fulfill such expectations.

\section{Purpose of the Study}

This article reports on a qualitative study carried out with a purposively selected group of teachers in Shurugwi to determine whether they are able to offer prevention education and care / support to learners by focusing on their perceptions, needs and insights into HIV and AIDS education. This approach is guided by the belief that the participants in any educational exercise have valuable input to offer and are an important part of the teaching-learning process. It is therefore essential that the lived experiences and needs of teachers are made known, before any steps are taken to help them develop in this regard. The development of knowledge, skills and critical insight into HIV and AIDS education is vital, since left unchecked, the contributory factors to and the consequences of the pandemic threaten to wipe out any progress made towards a socially just and democratic education. The research question which guided this study was: 'What are teachers' experiences and perceptions of HIV and AIDS education in their schools?'

\section{Research Methodology}

A qualitative approach was adopted, since the focus was on the perceived needs and beliefs of participants (Struwig and Stead, 2007). Sampling was purposive to select teachers who would be able to provide rich data on the topic of HIV and AIDS in schools. For this reason all participants selected were Guidance and Counselling teachers who are expected to educate learners about HIV and AIDS. A total of 24 teachers from schools in Shurugwi were interviewed before data saturation point was reached. The audio-taped and transcribed interviews were read and analysed to identify themes, ideas, emotions and opinions (Litchman, 2010).

\section{Discussion of Findings}

It was evident from the data analysis that Shurugwi teachers held varied and sometimes contradictory perceptions on HIV and AIDS. The data analysis revealed the following themes, discussed now in relation to relevant literature and supported by direct quotations from teachers.

\section{Theme 1: Teachers are constrained by their own socio-cultural backgrounds}

A male teacher who had just attended a two-day workshop on sexuality education was asked by his school head to implement what he had been taught at the workshop in his classroom and this is what he had to say: 'I won't be able to do this'. This remark highlights the tension between teachers' awareness of what they should be doing and what they actually feel comfortable with. Shurugwi secondary school teachers were acutely aware that they played a vitally important role in determining the extent to which issues such as sexuality of learners would be addressed. However, they stated that, along with most of their colleagues, they found it difficult to address prevention through sexuality education, to talk about HIV and AIDS openly and to take responsibility for integrating HIV and AIDS education into the teaching-learning process.

The participant teachers repeatedly mentioned that they were hesitant to discuss issues related to sexuality. They attributed this to the fact that traditional Shona culture does not encourage adults to speak to children about sex as reflected in the following teacher's response:

Sexuality is a closed subject amongst teachers. It is just not something people are comfortable with, even us [guidance and counselling teachers]. In fact I remember attending a workshop on HIV/AIDS and we had to come and report back but it was sort of an uncomfortable situation, especially among males.

Teachers understandably struggle to implement the Abstain-Be-Faithful-Condomise (ABC) approach promoted by both the Ministry of Health and Education. They consequently tend to avoid engaging with learners and 
potentially embarrassing questions, adopting a teacher-centred type of pedagogy (Visser, 2004). Male teachers may also construct themselves as sexual towards their female students (Chege, 2006), making it uncomfortable for young girls in the class to ask questions. In either case, critical discussion and exploration of sexuality and its link to HIV is not likely to take place.

As products of a gendered society, teachers also tend to unquestioningly accept the dominant norms and practices. For example, when the male teacher quoted above said he could not address sexuality issues in class, even after a two-day workshop, a female teacher described her reaction as follows:

Because I am passionate about this HIV/AIDS thing, I said OK, I will teach it as I learn about it. And gradually I introduced this sexuality thing in school.

The male teacher was thus relieved of the responsibility to integrate HIV and AIDS education into his teaching, because his female colleague accepted that he "can't do this." Although this response is indicative of the agency displayed by the female teacher, the fact that she did not think of challenging him to do what the curriculum calls for him to do, is suggestive of the prevailing male dominant power relations.

Although it is not easy to change attitudes and schemata acquired over time, raising critical awareness around cultural habits (Bourdieu, 1990) helps provide a theoretical lens through which to address transformation. One male teacher in Shurugwi district related how he had overcome his cultural embedded fear of addressing sexual matters through conscious effort and practice. Other studies confirm that males can and do change their gender constructs, given the opportunity to critically reflect on them (Macedo, 2006). Much of the current HIV and AIDS literature positions males as aggressive, dominant and sexual predators (Human Rights Watch, 2001), suggesting their unsuitability to address sexuality in the classroom. Helping male teachers to become more caring and approachable would open up the way for creating less polarized gender roles, thus contributing in a small way to changing the prevailing gender norms in education.

It is apparent from the responses of the participating teachers that they would benefit from exploring their gender constructs and sexual identities, as a first step in becoming more comfortable in adopting learner-centred approaches that will encourage open dialogue and critical discourse on the link between social norms and high-risk behaviours.

Most participant teachers highlighted the self-generated silence around HIV and AIDS. One teacher had this to say:

I have never heard that one [teacher] would admit that he has got HIV/AIDS. I think it is still a very sensitive subject.

Not only is there silence around being affected / infected among teachers, but there were many references to stigmatization between teachers.

But now what happened at this school, there was an argument between two lady teachers, the one was accusing the other, gossiping about the other one that she might be HIV positive, because her boyfriend was HIV positive.

One teacher indicated that this non-accepting attitude may be a product of their own fear:

People seem to entertain themselves about other people's problems shying away from their own problems. For instance I can gossip about someone who is HIV positive, meanwhile, I am also HIV positive, you see, or I don't even know my status.

Cohen (2002) suggests that teachers' refusal to acknowledge the existence of HIV and AIDS in their own lives, given that the pandemic is associated with sex, promiscuity, lack of education and poverty, is an unconscious attempt to protect their own self-image as a socially elite group within the community. Such thinking is hard to reconcile with the values that teachers are expected to convey to learners, namely, acceptance, tolerance and care for those who are HIV infected or affected. Against this background, it is disconcerting that teachers are not more open and are still displaying the very behaviour and attitudes that they are preaching as unacceptable to learners.

Most teachers avoid taking responsibility for HIV and AIDS education. The Guidance and Counselling teachers interviewed, all expressed that they felt overloaded and overburdened by their mandate to provide HIV education and support to the rest of the school - "we are very tired." It should be noted that Guidance and Counselling teachers who had been trained through short courses run by non-governmental organisations, were battling to implement education or prevention initiatives for two main reasons - lack of time and lack of cooperation from other teachers, ascribed as jealousy. 
I haven't done much on HIV and AIDS, because it is difficult. Sometimes you will find it depends on who is introducing this. Because there are camps, at our school they may not listen to what you say. If you are considered to be in an opposing camp even if you come up with something that is constructive, they won't listen to you.

When asked what the main challenges facing HIV education were, one teacher responded as follows:

Not being heard, when you are coming up with something that you think is good, something you think might help others, it might help yourself and other people. Because one teacher might think that you want to be seen as THE teacher.

The perception among participants was that teachers in general were scared to "open a can of worms" by addressing certain issues they felt they could not cope with. Thus in spite of the official policy that it is the responsibility of every Guidance and Counselling teacher to become actively involved in HIV and AIDS education, the responses in this study indicate that very few teachers are doing so. There are also indications that teachers' gendered views, embedded in a discourse of morality, may negatively influence how they approach the subject of gender relations in the classroom, as portrayed in the following quotation:

It is gentlemen who give us all these problems. If men were cautious, we wouldn't be in this problem. Most of the time we are at the mercy of men because if your partner doesn't want to practice safe sex how much more to those small kids, teenagers? If you say wear a condom and he says "why? Don't you trust me or are you being unfaithful to me? - that is why you want me to wear a condom." So I think if men are cautious, infection will be reduced.

Theme 1 has highlighted the fact that teachers are not confident about or comfortable with integrating HIV education and sexuality issues into their teaching, and what they teach is shaped by their own cultural beliefs and practices. This would suggest that there is a need to raise their critical consciousness (Freire, 2004) about how their own views could hinder or promote effective HIV and AIDS education.

\section{Theme 2: Teachers are hampered by structural constraints in their attempt to initiate a coherent response to address the challenges posed by HIV and AIDS}

Although the participating teachers were aware that they could not deal with the challenges that they were facing as a result of the impact of HIV and AIDS on the schools without working with other role-players, they did not know how to begin to build the required cooperation. All the teachers interviewed complained that the training they got from NGOs on HIV and AIDS education had mostly been focusing on bio-medical issues. Although this increased their knowledge about HIV transmission, it however, did little to help them address the related socio-cultural issues that impact on the academic performance of the learners and the quality of education in general. Teachers also had other needs that were not addressed, such as help with stress management:

That is one thing the Ministry of Education is failing us with. You know, everyday there is something new and it is stressful. You go home feeling, very tired and very down.

All the schools in Shurugwi had HIV and AIDS policies in place but according to the participants these mostly remained unimplemented. Coordination with the Ministry of Health and the Department of Social welfare was also problematic. With respect to the latter teachers reported occasionally financing food and medicine requirements for students affected by HIV and AIDS out of their own pockets. Although such a response is in keeping with Ubuntu and care for the less fortunate, it is impossible for individual teachers to provide for material needs of many learners on an ongoing basis. In terms of the Department of Health, teachers complained that clinics were often staffed with poorly trained volunteers who passed moral judgements on learners who were HIV positive or had sexually transmitted disease. These volunteers were also perceived to break confidentiality and disclose information to the wider community. As a result learners preferred going to clinics in other communities where they were not known.

\section{Theme 3: Teachers are overwhelmed by social problems surrounding HIV and AIDS}

Teachers interviewed felt incapacitated by the array of social problems facing learners, schools, parents and the community in terms of stigma and poverty often aggravated by traditional cultural beliefs. Community stigma was blamed for the lack of disclosure of HIV status, making it difficult for teachers to identify vulnerable learners. One teacher intimated that when he asked one boy in his class where his father was, the answer he got was "I don't know." On further investigation the teacher discovered that the father had recently died under conditions suspected, by the community to be HIV related. This is consistent with findings (Daniel, 2007) that the stigma experienced by people affected by HIV and AIDS leads to secrecy, as they try to maintain their sense of worth in the face of stringent community ideals and morals. No solutions for overcoming stigma were 
suggested by teachers, indicating that the call for teachers to adopt a humanizing and critical pedagogy (Macedo, 2006) to address cultural silence may go unanswered unless they are helped in this regard. In addition to the above, teachers also felt overwhelmed by the social consequences of poverty in Shurugwi district. The lack of food, inadequate clothing, neglect and sexual abuse were linked to the underlying problem of poverty in this district. Poverty means that learners cannot access adequate health care and that many students drop out of school, due to lack of money to pay school fees. Poverty was regarded by many Guidance and Counselling teachers as the main reason why girls entered into relationships that increased their vulnerability to abuse, pregnancy and HIV Infection as evidenced by the following teacher's remark:

Another problem is the family's poverty whereby women depend on men for support. Women and girls do everything men want because they want to get the money. Even the girls here at school depend on men to get their school things. They do everything men want to get support from the men

The helplessness felt by Guidance and Counselling teachers is evident in their voices and points to the fact that they need to be assisted to view the pandemic, not as a paralyzing catastrophe but as an opportunity to mobilize community assets and strengths to find workable solutions.

Shurugwi teachers were aware that cultural barriers were hampering HIV and AIDS education such as the taboo about addressing sexual issues, gender inequalities and the tendency to attribute HIV and AIDS to something other than the virus. In this connection the area coordinator for Guidance and Counselling teachers remarked:

There is lack of respect in this district. Boys do not respect girls. That is one of our problems. In our culture boys are superior to girls and so when boys engage in affairs with girls they don't respect the girls. There are also times in this community and culture where they don't really believe that there is such an illness as HIV/AIDS

Teachers complained that education did not seem to have an impact on the behaviour of learners since they continued to engage in unsafe sex and displayed gendered attitudes. They were at a loss as to how cultural attitudes and beliefs could be changed towards practices that rendered learners less vulnerable to HIV infection. Cultural beliefs are indeed difficult to change since they are usually accompanied by cultural silence that prohibits discussion about issues that underlie social structures that preserve existing power relations. Cultural silence also helps to promote denial, since it is easier to hide behind the 'we don't talk about it in our culture' attitude than to cope with the difficult questions and challenges that critical discussion would generate (Daniel, 2007).

\section{Conclusion and Discussion}

The themes emerging from the data provide robust evidence to support literature that portrays schools as spaces where the consequences of the HIV and AIDS pandemic are acutely experienced by teachers (Theron, 2007). There is a strong indication that teachers would benefit by interventions to raise their critical consciousness around how their attitudes and beliefs may influence teaching. This would be the first step in enabling teachers to break free from culturally imposed constraints to seek more workable appropriate ways to educate learners to become critically aware themselves of alternative responses to HIV and AIDS. The predominant view of HIV and AIDS presented by teachers focused on the destructive impact of the pandemic on education, ignoring the potential for positive change. This created a vicious cycle of hopelessness, helplessness and despair at Shurugwi schools. Despite previous studies highlighting the need for a response to support teachers to adopt a more critical stance to HIV and AIDS education (Bennell, 2005), it appears that teachers continue to position themselves as the helpless victims of a dysfunctional society, thereby increasing their sense of powerlessness and frustration.

The development of teachers to implement HIV and AIDS education in Shurugwi district needs to be prioritized. This could be facilitated by a critical pedagogical approach aimed at raising awareness among teachers of the need to interrogate, deconstruct and reconstruct their social and cultural identities in relation to how they educate around HIV and AIDS. Critical consciousness raising will also serve as the first step in breaking down the culture of dependency that resonates from the thematic analysis, and help to reposition teachers to perceive themselves as agents of social change. Once such insight is nurtured, teachers will be in a better position to critically evaluate existing social, political and cultural structures and practices, to envision alternative realities, and to pass on this vision to learners.

The findings of this study seem to indicate that HIV and AIDS education for teachers has to be radically transformed both at pre - service and in -service levels. We need to find ways to encourage teachers to critically engage with the causes and consequences of the pandemic; to raise an emotionally supportive environment in which to do this; to protect their own well - being and that of the learners; and to view HIV and AIDS as a 
catalyst for educational improvement rather than as an unmitigated, unstoppable disaster. This would entail a perceptual shift from training to learning about what shapes them and their teaching around HIV and AIDS; from giving answers to asking more questions, enabling teachers to think differently as a precursor to behavioural change; from telling them what to do to listening to what they need, involving them in their own development and encouraging reflective practice. In conclusion the voices of the teachers in this study need to be heeded to promote the likelihood that teaching around HIV and AIDS is contextually relevant. It would be unfair to expect Shurugwi teachers to deal with the challenges of HIV and AIDS without first helping them to critically explore how the issues emerging from this study could be addressed.

\section{References}

Bennell, P. (2005). The impact of the Aids epidemic on teachers in sub - Saharan Africa. Journal of Development Studies, 41(3), 5-23.

Berger, J. (2004). Re-sexualizing the epidemic: desire, risk and HIV prevention. Development Updat, 5(3). Retrieved from http://www.sarpn.org.za/documents

Bourdieu, P. (1990). The logic of practice Cambridge: Polity Press.

Chege, F. (2006). Teachers' gendered identities, pedagogy and HIV/AIDS education in African settings. Journal of Education, 38, 25-44.

Cohen, D. (2002). HIV and education in sub - Saharan Africa: responding to the impact. Perspectives in Education, 20(2), 13-27.

Coombe, C. (2002). HIV /AIDS and education. Perspectives in Education, 20(2), 36-40.

Clarke, D. (2005). Planning and evaluating for gender equality in the context of HIV and AIDS. Retrieved from http://www.ungei.org/resources

Daniel, M. (2007). Breaching cultural silence: enhancing resilience in Ugandan orphans. African Journal of AIDS Research, 6(2), 110-122. http://dx.doi.org/10.2989/16085900709490405

De Lannoy, A. (2005). Vulnerability, care and support in and through schools: review of school base research. Cape Town: University of Cape Town.

Freire, P. (2004). Pedagogy of Indignation, Colorado: Paradigm Publishers Human Rights Watch (2001). Scared at school: sexual violence against girls in schools. Washington: Human Rights Watch

Macedo, D. (2006). Humanizing pedagogy through HIV and AIDS prevention: transforming teacher knowledge. Colorado: Paradigm Publishers

Struwig, F., \& Stead, G. (2007). Planning, designing and reporting research. Cape Town: Maskew Miller.

Theron, L. (2007). Educator perceptions of learners' HIV status. South African Journal of Education, 25(1), 52-69.

Visser, M. (2004). Addressing the impact of HIV/AID. Maputo: Unicef. 